\title{
Hypothetical Thresholds for Effects of Platinum Group Elements
}

\author{
Gunnar Bengtsson ${ }^{1}$ \\ ${ }^{1}$ Ekerö, Sweden \\ Correspondence: Gunnar Bengtsson, Luruddsvägen 32, SE-17854 Ekerö, Sweden. Tel: 46-70-730-5482. E-mail: \\ gunnarbengt@telia.com
}

Received: February 2, 2019

Accepted: March 25, $2019 \quad$ Online Published: March 31, 2019

doi:10.5539/ep.v12n1p39

URL: https://doi.org/10.5539/ep.v12n1p39

\begin{abstract}
The platinum-group elements are rhodium, ruthenium, palladium, osmium, iridium, and platinum. Together with rhenium and gold they form the highly siderophilic ("iron-loving") elements. These are poorly known with respect to toxicity and ecotoxicity.

The mobilization by man of the eight metals is about 100 times to 1 million times the natural mobilization. Mean soil concentrations in Europe may now be more than doubled for gold, rhenium and rhodium. The objective of the current work was to enable a preliminary assessment of the consequences of such high environmental levels.

Thresholds for ecological effects found in the literature were divided by the element's mean soil concentration and plotted against group and period in the periodic system. Thresholds for health effects were correspondingly divided by the mean dietary intake of the element over large population groups.

For health effects, an upper limit of intake is commonly used. This was shown to be about 4 times the mean normal intake for most period 4 elements. For other periods, occupational exposure thresholds entail upper limits of intake in $\mu \mathrm{g}$ /day of: Ru 18, Rh 8, Pd 17, Re 60, Os 15, Ir 4, Pt 20 and Au 160.

For ecological effects, the no effect thresholds for period 4 were 1-5 times the soil concentrations. Very scarce data suggest higher relative thresholds for periods 5 and 6 .

The current high contaminations of European soil by Rh and possibly Pd may be of concern. Since the estimates of risks are uncertain, further research is warranted.
\end{abstract}

Keywords: natural elements, platinum group, siderophilic, threshold, transition metals, upper limit of intake

\section{Emerging Contaminants with Little Toxicity Information}

\subsection{Platinum Group Elements Exposures Have Multiplied in Recent Decades}

The platinum-group elements (PGEs) are rhodium, ruthenium, palladium, osmium, iridium, and platinum. These form the group of noble metals together with, rhenium, gold, copper, silver, and mercury. The health and environmental properties of the latter three are comparatively well known. In contrast, properties of the former eight elements are poorly known with respect to toxicity and ecotoxicity. This is to a large extent due to their extremely low concentrations in nature; for instance, the soil concentrations of all these elements are less than one-third of that of the next lowest concentration element (tellurium). The eight elements are highly siderophilic ("iron-loving") (Day, Brandon \&Walker, 2016). In addition, molybdenum was included among the siderophile elements in the original Goldschmidt classification (Goldschmidt, 1937) although its classification has been disputed and its concentration in soil is more than 200 times higher than that of the other siderophiles. Further, sometimes neighboring elements such as cobalt, nickel, silver and tungsten are called siderophile. The purpose of the current review is to suggest plausible ranges for the no effect thresholds of the eight highly siderophile elements.

Over the last half century, the world production of platinum group elements has increased more than tenfold (Zientek, Loferski, Parks, Schulte, \& Seal, 2017). They have excellent properties i.a. with respect to catalytic action, wear, and chemical attack and are widely used in industry. In industrial processes they are for instance used to manufacture nitric oxide, specialty silicones or refined oil products. Major uses concern catalysts to decrease automobile exhaust emissions. Jewelry and investment metals are other examples of uses (Zientek et. al., 2017). The PGEs are among the technology-critical elements that are of great relevance in the development of emerging key technologies (Cobelo-Garcia et. al., 2015). Rhenium has similar properties but more limited 
uses and production volumes (John, Seal, \& Polyak, 2017). Gold also has similar properties but has a longer history of use. It is the most produced element in the group but still production for its wide array of uses has about triplicated over the last half century (United States Geological Survey [USGS], 2018).

The mobilisation by man of the eight metals is about 100 times to 1 million times the natural mobilization (United Nations Environment Programme [UNEP], 2013). It is therefore to be expected that their environmental levels today should be enhanced over the natural ones. Indeed, it has been estimated that in Europe, mean soil concentrations have been more than doubled for gold, rhenium and rhodium (Bengtsson, 2018). This entails that soil concentrations in large areas have increased more than ten-fold.

\subsection{Little Information Exists on Toxcicity and Ecotoxicity}

The consequences for environment and health of such increases are difficult to assess. A typical statement by assessors reads: "Broader human health effects of PGEs appear to be limited because of the low concentrations of PGEs in the environment" (Zientek et. al., 2017); those authors do not even address ecological thresholds for the elements under their heading "Ecological Health Concerns". A recent review summarizes "No information is available for rhenium and its toxic effects on humans, partly (presumably) because of its low natural abundance" (John et. al., 2017), and a parallel statement is made for toxic effects on aquatic or terrestrial ecosystems. For gold, there has been an increased study of gold nanoparticles (Moreno-Garridon, Pérez, \& Blasco, 2015; Yah, 2013; Fratoddi, Venditti, Carnetti, \& Russo, 2014; Avellan et. al., 2018; Weaver et. al., 2017) including transgenerational effects by maternal exposure (Kim, Kwak, \& An, 2013). Rarely, also ionic gold has been included (Botha, James, \& Wepener, 2015). A European Food Safety Authority [EFSA] ANS Panel (2016) noted the absence of toxicological data on gold used as a food additive and considered the data to be too limited to perform a risk assessment for the additive. Similarly, lack of data for effects of pharmaceutical impurities prompted the application of very high safety margins in setting permitted daily exposures for gold (International Council for Harmonisation of Technical Requirements for Pharmaceuticals for Human Use [ICH], 2014).

\subsection{Exploring the Possibility to Extrapolate across the Periodic System of Elements}

Some of the highly siderophilic elements are thus mobilized to an extremely large extent compared to natural mobilization. Several of them are likely to already exhibit enhancements of mean European soil levels that are higher than enhancements of any other elements. At the same time, very little information exits on the consequences of these enhancements for health and the environment. The combination of high exposures and little knowledge of consequences begs innovative approaches to estimate thresholds for health and environmental effects.

\subsubsection{Parameters of the Periodic System}

One possibility derives from the systematics of the periodic system of elements. For instance, the transfer factor from soil to human intake of elements 21-30 ( $\mathrm{Sc}, \mathrm{Ti}, \mathrm{V}, \mathrm{Cr}, \mathrm{Mn}, \mathrm{Fe}, \mathrm{Co}, \mathrm{Ni}, \mathrm{Cu}, \mathrm{Zn}$ ) follows a power function of the atomic number or of the geometrical mean of the first three ionization energies, with a coefficient of determination in the range $0.93-0.96$ (Bengtsson, 2018). This function has a steep discontinuity between groups 7 and $8(\mathrm{Mn}$ and $\mathrm{Fe}$ ). The iron connection is interesting since the highly siderophilic elements dissolve readily in iron and are depleted in the upper continental crust since they have tended to sink into the earth's core (Day et. al., 2016). The discontinuity elements mark the starting group numbers of the highly siderophilic elements (Ru in period 5, Re in period 6). The Mn-Fe discontinuity might thus be expected to have parallels for thresholds near $\mathrm{Ru}$ and $\mathrm{Re}$ in the periodic system. Parameters beyond atomic number and ionization energy that have proved useful to describe biological effects include for instance electronegativity and the ratio atomic radius/atomic weight (Qie et. al., 2017). For human health effects, complex stability constants, electrochemical potential, and covalent index were useful in predicting effect doses (Wang et. al., 2018).

\subsubsection{Reference to Natural Exposures}

Another possibility of extrapolation derives from the known adaptation of organisms to natural concentrations of elements in the environment. Microorganisms are masters of adaptation and have many mechanisms by which they can become resistant to stressors such as metals (e.g. Gaze et. al., 2013; Brooks, Turkarslan, Beer, Fang, \& Baliga, 2011). Significant correlation has indeed been found between antibiotic resistance genes and soil metal concentrations (Knapp et. al., 2011, Knapp et. al., 2017). Many effects have been correlated with freshwater and soil concentrations of natural elements (Walker, Enache, \& Dearden, 2003). The significance of adaptation has been discussed in the concept of metalloregion (Fairbrother \& McLaughlin, 2002), according to which soil organisms may adapt to their natural surrounding leading to a shift in the levels at which the soil is affected. It has also been recommended that future design of toxicology experiments should attempt to incorporate the 
dosage rate or the dietary influx rate to facilitate inter-comparison of the results of different studies (Wang, 2013). It is thus a natural hypothesis to assume that thresholds for health and environmental effects would be closely related to the natural exposures of the elements.

\subsubsection{Hypothesis: Periodic System and Natural Exposures might Enable Extrapolation to Siderophiles}

These two possibilities combined (atomic parameters and natural exposures) invite the hypothesis that thresholds for effects of siderophile elements might be obtained from the trends of thresholds across the periodic system arranged by the system's groups and periods. References to natural exposures might be useful. Discontinuities might be expected at the groups where the siderophile elements begin (group 7) and end (group 11). Other parameters such as ionization energies or electron affinity might possibly assist in refining the trends.

\subsection{Objective and Scope}

The objective of the current work is thus to

- look for parameters that describe trends of thresholds for health and environmental effects across the periodic system of elements

- that might entail credible estimates of thresholds for highly siderophilic elements

- which would enable a preliminary assessment of the consequences of high environmental levels of those elements.

In this search, elements that are likely to deviate from the general trends should be deselected, such as non-stable elements or noble gases.

\section{Method}

To meet the objective, eligible elements should be selected. Natural concentrations of these elements should be defined. Measures of exposures should be discussed, for instance soil and sediment concentrations or amounts of daily intake. Data on toxicity and ecotoxicity thresholds should be selected. Parameters of the periodic system that might help establish trends in these data should be explored. Several approaches for estimating thresholds for siderophile elements should be compared. The methods for selection and analysis are detailed in the following. The selected data are presented in table 1.

\subsection{Selection of Elements}

Several elements or groups in the periodic system are expected to have quite different properties making extrapolation to the siderophile elements difficult and are deselected

- Elements in groups 1-3 and 15-18 are more than 3 groups away from elements in the siderophile groups $7-11$

- Of elements in the remaining groups $4-14$, technetium is radioactive and radiation effect might confound other biological effects

- Group 13 elements $(\mathrm{Ga}, \mathrm{In}, \mathrm{Tl})$ break the trend of first ionization energies increasing with atomic number. Neither does the third ionization energy follow the trend of the transition metals.

- Since group 13 elements are deselected, elements in group 14 (Ge, $\mathrm{Sn}, \mathrm{Pb})$ have a gap to lower group elements in the same period that renders extrapolation more uncertain.

This deselection leaves for further study the transition metals except the extended rare earths in group 3 and technetium. These transition metals can have similar physicochemical properties and mechanisms of toxicity since they are similar in electronic structures (Walker et al., 2003).

\subsection{Availability of Suitable Data}

For extrapolation of data to be meaningful, it should start from a set of element data that has been derived in a coherent way, preferably under the scrutiny of many different scientists. For the current analysis, therefore, isolated data derived from databases of exposures or toxicological and ecotoxicological effects would be avoided.

It would also be preferable to have available data for at least two elements from groups below the highly siderophile elements groups, that is, at group 6 or below, and two groups above, that is, at groups 11 or 12 or above. With the deselection of group 13 elements, this criterion cannot be met for gold in period 6 .

Data on exposures such as concentrations in soil or water or daily intakes can be found for almost all elements of interest. 
Data on human health and environmental effects are available for many of the selected period 4 elements. For periods 5 and 6, mainly $\mathrm{Cd}$ and $\mathrm{Hg}$ have been assessed, in a few cases also Mo and $\mathrm{Ag}$. Compilations of threshold data are available, e.g. Ministry for the Environment New Zealand [MFE] (2019). Data are also available for several correction factors for soil thresholds for a small number of elements (ARCHE Consulting, 2019). Such a degree of refinement has not been sought but rather robust and simplified default values for the most common parameters have been used.

More elements have been evaluated for human occupational exposures, including many elements in periods 5 and 6, albeit for some elements not by broad assessor groups.

\subsection{Natural Exposures to the Selected Elements}

\subsubsection{Mean Soil Concentrations}

The mean soil concentrations of Europe (Forum of European Geological Surveys [FOREGS], 2005) have been the basis for soil concentrations. They have been supplemented to cover all selected elements as described by Bengtsson (2018). Anthropogenic components have been subtracted.

Table 1. Basic data used in the derivation of figures 1-3.

\begin{tabular}{|c|c|c|c|c|c|c|c|c|c|c|c|c|c|c|c|c|c|c|}
\hline & \multirow[t]{2}{*}{ z } & \multirow[t]{2}{*}{ G } & \multirow[t]{2}{*}{$\begin{array}{l}\text { Soil } \\
\text { conc. } \\
\mathrm{mg} / \mathrm{kg}\end{array}$} & \multirow[t]{2}{*}{$\begin{array}{l}\text { Diet. } \\
\text { intake } \\
\mu \mathrm{g} / \mathrm{da} \\
\mathrm{y}\end{array}$} & \multirow[t]{2}{*}{$\begin{array}{l}\mathrm{D} . \\
\text { magna } \\
\text { EC50 } \\
\mu \mathrm{g} / \mathrm{l}\end{array}$} & \multirow[t]{2}{*}{$\begin{array}{l}\text { Diss. } \\
\text { conc. } \\
\mu \mathrm{g} / \mathrm{l}\end{array}$} & \multicolumn{4}{|c|}{$\begin{array}{c}\text { Threshold for soil } \\
\text { organisms } \\
\mathrm{mg} / \mathrm{kg}\end{array}$} & \multicolumn{4}{|c|}{$\begin{array}{l}\text { Threshold for human intake } \\
\qquad \mu \mathrm{g} / \text { day }\end{array}$} & \multirow[t]{2}{*}{$\begin{array}{l}\text { Geom } \\
\text {. diet }\end{array}$} & \multicolumn{3}{|c|}{ Occupational thresholds } \\
\hline & & & & & & & $\begin{array}{c}\text { Finl } \\
.\end{array}$ & Sw. & $\begin{array}{l}\mathrm{Ca} \\
\mathrm{n} .\end{array}$ & UK & NAS & EFSA & $\mathrm{ICH}$ & Geo. & & $\begin{array}{l}\text { Inha-lati } \\
\text { on } \\
\mathrm{mg} / \mathrm{m} 3\end{array}$ & $\begin{array}{l}\text { Oral/ } \\
\text { inha-lati } \\
\text { on }\end{array}$ & $\begin{array}{l}\text { Threshold/ } \\
\text { intake }\end{array}$ \\
\hline $\mathrm{Ti}$ & 2 & 4 & 3359 & 300 & 5700 & 10 & & & & & & & & 6000 & 200 & 5 & 100 & 200 \\
\hline V & 2 & 5 & 68 & 15 & 1200 & 1 & 10 & 10 & 130 & & 1800 & & 100 & 424 & 28,3 & 0,05 & 100 & 28 \\
\hline $\mathrm{Cr}$ & 2 & 6 & 83 & 50 & 130 & 1 & 10 & 80 & 64 & & 1070 & & 1070 & 1070 & 214 & 0,5 & 3690 & 214 \\
\hline$M$ & 2 & 7 & 460 & 3500 & 9300 & 8,2 & & & & & 1099 & & & 1099 & 3,14 & 0,2 & 100 & 3,8 \\
\hline $\mathrm{Fe}$ & 2 & 8 & 21700 & 1000 & 2300 & 40 & & & & & 4500 & & & 4500 & 4,5 & 5 & 100 & 3,8 \\
\hline Co & 2 & 9 & 10,4 & 10 & 710 & 0,2 & 20 & 15 & 40 & & & & 50 & 50 & 5 & 0,005 & 100 & 3,8 \\
\hline $\mathrm{Ni}$ & 2 & 1 & 37,3 & 150 & 650 & 0,5 & 50 & 40 & 45 & & 1000 & & 200 & 447 & 2,98 & 0,05 & 40 & 3,8 \\
\hline $\mathrm{Cu}$ & 2 & 1 & 17,3 & 1300 & 13 & 1,5 & 10 & 80 & 63 & 14 & 1000 & 5000 & 3000 & 5313 & 4,09 & 0,1 & 100 & 3,8 \\
\hline $\mathrm{Zn}$ & 3 & 1 & 68 & 1000 & 720 & 30 & 20 & 25 & 250 & 27 & 4000 & 2500 & & 3162 & 3,16 & 5 & 10 & 3,8 \\
\hline $\mathrm{Zr}$ & 4 & 4 & 223 & 30 & 2900 & & & & & & & & & & & 5 & 100 & 200 \\
\hline $\mathrm{Nb}$ & 4 & 5 & 9,79 & 20 & 140 & & & & & & & & & & & 5 & 100 & 212 \\
\hline M & 4 & 6 & 0,79 & 100 & 15000 & 0,5 & & 40 & 5 & & & & & & & 0,5 & 300 & 107 \\
\hline $\mathrm{Ru}$ & 4 & 8 & 0,0001 & 0,3 & & & & & & & & & & & & & & $40^{*}$ \\
\hline $\mathrm{Rh}$ & 4 & 9 & 0,0001 & 0,5 & 290 & & & & & & & & & & & 0,001 & 100 & 15 \\
\hline $\mathrm{Pd}$ & 4 & 1 & 0,0041 & 1 & & & & & & & & & & & & 0,0015 & 100 & 17, \\
\hline $\mathrm{Ag}$ & 4 & 1 & 0,280 & 30 & 0,91 & 0,3 & & 1,2 & 20 & & & & & & & 0,01 & 21,4 & 16, \\
\hline $\mathrm{Cd}$ & 4 & 1 & 0,182 & 10 & 3,6 & 0,02 & 1 & 4 & 3,8 & 2 & & & & & & 0,005 & 2,5 & 3,8 \\
\hline $\mathrm{Hf}$ & 7 & 4 & 5,40 & 1 & 9700 & 0,01 & & & & & & & & & & 0,5 & 100 & 600 \\
\hline $\mathrm{Ta}$ & 7 & 5 & 0,714 & 1 & 4,6 & $0,001 *$ & & & & & & & & & & 5 & 100 & 424 \\
\hline W & 7 & 6 & 1,5 & 3 & 30000 & & & & & & & & & & & 1 & 480 & 713 \\
\hline $\mathrm{Re}$ & 7 & 7 & 0,0002 & 0,03 & 58000 & & & & & & & & & & & & & 200 \\
\hline Os & 7 & 8 & 0,0001 & 0,02 & 8 & & & & & & & & & & & 0,002 & 100 & 610 \\
\hline Ir & 7 & 9 & 0,0000 & 0,02 & 3000 & & & & & & & & & & & & & 250 \\
\hline $\mathrm{Pt}$ & 7 & 1 & 0,0017 & 0,2 & 140 & & & & & & & & & & & 0,002 & 100 & 114 \\
\hline $\mathrm{Au}$ & 7 & 1 & 0,005 & 1 & 29 & 0,002 & & & & & & & & & & 0,007 & 100 & 162 \\
\hline & 8 & 1 & & & & & & & & & & & & & & & & 47 \\
\hline $\mathrm{Hg}$ & 0 & 2 & 0,061 & 4 & 0,65 & 0,1 & 0,5 & 5 & 12 & & & & & & & 0,025 & 30 & 6 \\
\hline
\end{tabular}

Notes. $\mathrm{Z}=$ atomic number; G=group in the period system; NAS, EFSA, ICH derived from references NAS, 2001, EFSA, 2006, ICH, 2014; Diss. conc. $=$ Dissolved element concentration; Geom/diet=geometrical mean of upper limits of intake for NAS, EFSA and ICH divided by mean dietary intake; Threshold/intake=Occupational threshold converted to daily intake divided by mean daily intake *Interpolated $* *$ For Ta 73 One-half of the detection limit 


\subsubsection{Mean Human Dietary Intakes}

The mean daily human dietary intakes over large population groups refer to the mean of adult male and female intakes in Europe although data from outside Europe were also used in their derivation. They pertain to intakes from natural sources, so anthropogenic sources have been corrected for. The methods are described in detail in Bengtsson, 2018, and the data sources are given in the Appendix of Bengtsson, 2018.

\subsection{Selection of Data on Toxicity and Ecotoxicity Thresholds}

In general, the interest is in thresholds for effects rather than various kinds of established effects. Exceptionally, non-threshold studies could be included where many elements have been investigated by coherent methods, including the siderophile elements themselves. This might give clues to the extrapolation from non-siderophile elements. Only one corresponding research paper has been located. This concerns the half maximal effective concentration (EC50) for immobilization in Daphnia magna (Okamoto, Yamamuro, \&Tatarazako, 2014). The authors obtained EC50 results for 18 of the selected 26 elements. Of the 8 highly siderophile elements, results were obtained for 5 elements.

Some sets of threshold data have been deselected because they encompassed few elements or have resulted from a mixture of criteria, such as involving human health, ecological effects, visual appearance or smell. For such reasons data on thresholds for various types of water (International Water Resources Association [IWRA], 2018) or sediments were not used.

Data have been deselected if they were derived by using various assessment factors to account for uncertainties, for instance in extrapolating from animals to man. Such combined assessment factors might reach 100000 and would prevent meaningful extrapolation. One exception to this for permitted human exposures (ICH, 2014) has been used because 6 siderophile elements have been included; this might give clues that could give perspective on the extrapolation

\subsubsection{Daphnia EC50}

Okamoto et al. (2014) have applied OECD Test guideline 202 which tests the immobilization of Daphnia magna. In addition, they quoted result for 6 elements obtained by Biesinger \& Christensen, 1972. No results were given for $\mathrm{Ru}$ and $\mathrm{Pd}$, for which a physical effect was noted that did not enable assessment of the biological effect.

A single species effect would be expected to vary strongly with for instance test conditions and across elements. In recognition of this, a species sensitivity distribution is often used. The minimum size of the data set that can be employed for analyses of such distributions is disputed but a pragmatic choice in the Netherlands has been to use a minimum number of four species for deriving environmental quality criteria (Aldenberg \& Slob, 1993).

Because of the paucity of data, species sensitivity distributions could not be used in the current assessment. To reduce the variability, two approaches were employed. The first approach was to normalize the values of EC50 to the corresponding soil concentrations on the hypothesis that effects on Daphnia were conditional to the natural water concentrations that would be approximately proportional to the soil concentrations. The enhancements in elements of groups 4-12 for periods 5 and 6 over period 4 were calculated and the geometric mean enhancements for periods 5 and 6 were derived. The resulting geomean enhancements were plotted against group number.

The second approach was to compare the D. magna results with those from other test conditions. Data for two other test cases (D. magna (hardness $240 \mathrm{mg} / \mathrm{L}$ ) and C. subglobosa) from three other publications were listed by Okamoto et. al., 2014. These EC50 values were normalised to soil concentrations and averaged over periods 5 and 6 , and the geometrical means of the result for the two test conditions was derived.

To give a perspective on threshold effects for period 4 elements, the EC50 concentrations for D. magna were compared with the dissolved element concentrations in world rivers obtained by Martin \& Whitfield, 1983, as presented by Smith \& Huyck, 1999. The EC50 concentrations were divided by 100 to give the approximate no effect concentrations; May et. al., 2016, have suggested that an acute-to-chronic extrapolation factor of 100 is protective for more than $90 \%$ of the chemicals they studied. The quantity EC $50 * 0.01 /$ (dissolved concentration) was entered in the same diagram as the period 5 and 6 to period 4 ratios.

\subsubsection{Soil Thresholds}

Three sets of thresholds for effects on soil organisms have been selected:

- MEF, 2007; the threshold values for eligible elements have all been defined on ecological grounds by authorities in Finland 
- Swedish environmental protection agency, 2016; guideline values for simplified risk assessment for remediation of contaminated sensitive soils. Criteria have been that the soil ecosystem should be able to carry out the functions expected for the planned use of the area. It is assumed that this function would be preserved if most animals and plants that would exist in the area under uninfluenced conditions would be protected. About $75 \%$ of the species would be protected if the guideline values for sensitive soil are applied. For $\mathrm{Cd}$ and $\mathrm{Hg}$, human health effects have defined the default guideline value but in the current assessment the thresholds for effects on soil organisms have been used.

- CCME, 2019; The Canadian soil quality guidelines for agricultural land have been used. For $\mathrm{Cd}$ and $\mathrm{Hg}$, human health effects have defined the default guideline value but in the current assessment the thresholds for effects on soil organisms have been used.

The thresholds for each of the eligible three sets were divided by the mean soil concentrations derived as discussed above. The geometric means of the three sets was calculated and used to discuss the results.

Further, information on three elements $(\mathrm{Cu}, \mathrm{Zn}, \mathrm{Cd})$ was obtained from long term multi-soil experiments in the United Kingdom (UK Water Industry Research Limited, 2007). The research established no-effect thresholds for soil microorganisms. Among all identified experiments, this was the research performed closest to realistic field conditions, going over many years in many different soils. The thresholds should be very realistic and could be used to corroborate the realism of the other sets of thresholds.

\subsubsection{Human Toxicity: Baseline upper Limit for Dietary Intake for Period 4}

Period 4 elements might form baselines for the extrapolation to highly siderophile elements since the period does not contain such elements. Upper limits for dietary intakes of period 4 elements have been established by the Institute of Medicine, Food and Nutrition Board (2001; V, Mn, Fe, Ni, Cu, Zn) and EFSA (2006; Cu, Zn). In addition, titanium dioxide has recently been assessed by EFSA. That assessment is still controversial. Winkler, Notter, Meyer, and Naegeli (2018), have tentatively suggested safe upper levels of intake of $\mathrm{TiO}_{2}$ in the range 0.4 $-5 \mathrm{mg} / \mathrm{kg} /$ day, corresponding to a geometric mean daily intake of $60000 \mu \mathrm{g}$ of Ti for an adult $70 \mathrm{~kg}$ human.

Chromium in food generally occurs as CrIII. Few serious adverse effects have been linked to high intakes of chromium, so the Institute of Medicine has not established a Tolerable Upper Intake Level (UL) for this mineral (Institute of Medicine, Food and Nutrition Board, 2001).

Further, exposure to contaminants of medical drugs has been considered in depth. A list of human Permitted Daily Exposures including those of many siderophile elements has been compiled (ICH, 2014). The thresholds selected have for less studied elements been derived using very large safety margins (up to 100000 times) for extrapolations from uncertain data. It was still hoped that the data would assist in forming hypotheses about thresholds for human exposures. For period 4 elements, the effects were reasonably well known, and safety margins were less applied. A permitted daily exposure has been set for CrIII and this was the only found source for $\mathrm{Cr}$.

The data for oral exposure divided by the mean dietary intakes over large population groups were used to define the baseline for period 4 elements. The geometrical mean of the upper limits of EFSA, the Institute of Medicine, Food and Nutrition Board, and the mentioned oral intake data of ICH (2014), was identified. When two or more intakes were available, the range of the values was $0.2-5$ times the geometrical mean. The upper limit divided by the mean dietary intake averaged across elements in groups 7-12 was 3.81 with a standard deviation of 0.78 . Since the range was so narrow, a default value of 3.81 was selected as the baseline for groups $7-12$. For the groups 4-6, the geometrical means divided by mean dietary intakes were selected as baseline (Ti: 200; V: 28.3; Cr: 220)

\subsubsection{Human Toxicity Occupational Exposures Periods 5 and 6}

Comprehensive tables of time weighted average threshold limit values for occupational exposures are available for several countries or states. The table for California Department of Industrial Relations, 2019, is up to date. Its thresholds are generally the same as or lower than those for Canada (Canadian Centre for Occupational Health and Safety, 2019)) and Australia (safe work Australia, 2018). The data from California were selected with the exception of cobalt, where instead the recently discussed proposed value for Ontario was selected (Ontario Ministry of Labour, 2019). Lacking entries for California, thresholds for the following elements were gathered from Institut für Arbeitsschutz der Deutschen Gesetzlichen Unfallsversicherung [IFA] (2019):

- niobium, applied by Denmark and Austria

- tungsten, applied by Israel and Québec, Canada 
- $\quad$ palladium, applied by Finland.

No data were found for $\mathrm{Ru}, \mathrm{Re}$ and Ir. For $\mathrm{Au}$, the geometric mean of the entries for the neighboring Pt and $\mathrm{Hg}$ was used.

The entries pertaining to soluble metals were chosen when available, else the entries for insoluble compounds, metals or dust were selected. Special compounds mostly had thresholds within a factor of 10 from the chosen value. For chromium the only found baseline value for period 4 concerned CrIII (section 2.3.3) and the corresponding occupational limit was selected for the normalization of occupational exposures against the baseline values.

The median of the permitted exposures for inhalation is $1 \%$ of that for oral exposure (ICH, 2014). The just mentioned entries are corrected to correspond to oral intakes using the ratio of oral to inhalation threshold intakes of ICH, 2014, interpolated as given in table 1.

The threshold values in $\mathrm{mg} / \mathrm{m}^{3}$ were converted to mean daily intakes over a year by multiplication with $10\left(\mathrm{~m}^{3}\right.$ inhaled per day) * $1000(\mu \mathrm{g} / \mathrm{mg}) * 220$ (working days per year) / 365 (total days in a year).

The estimated daily threshold intakes corrected to represent oral exposures were divided by the mean daily intakes over large populations (section 2.2.2). Across elements in period 4, the geometrical mean of this ratio threshold/intake was 0.51 times that of the tolerable upper limit of intakes for adults in the general population, and the ratio had a range of $0.09-0.79$ of the upper limits. For the current purpose of extrapolation to siderophile elements, the occupational thresholds for periods 5 and 6 were normalized to correspond to the baseline upper limits of period 4. Those period 5 and 6 thresholds were multiplied by the ratio of baseline upper limits of period 4 and occupational thresholds of period 4 . The results are also entered in table 1.

2.4.5 Proportionality Check of the Extrapolation for Periods 5 and 6 Using Permitted Human Exposures from Pharmaceticals

As mentioned in section 2.3.3, permitted human exposures to many siderophile elements have been assessed (ICH, 2014), often with very large safety margins. The exposure for Cr was not used; it was based on CrIII while the occupational exposure limit selected was based on the 100 times more hazardous CrVI. Even though the impurity relevant values are very uncertain and expected to err on the side of safety, they might give some perspective to the extrapolation which is mainly based on occupational exposures (section 2.3.4). The permitted exposures for elements in periods 5 and 6 were divided by the mean dietary intakes.

\section{Results}

3.1 Daphnia EC50

Data from exposures of aquatic organisms are given in figure 1. 


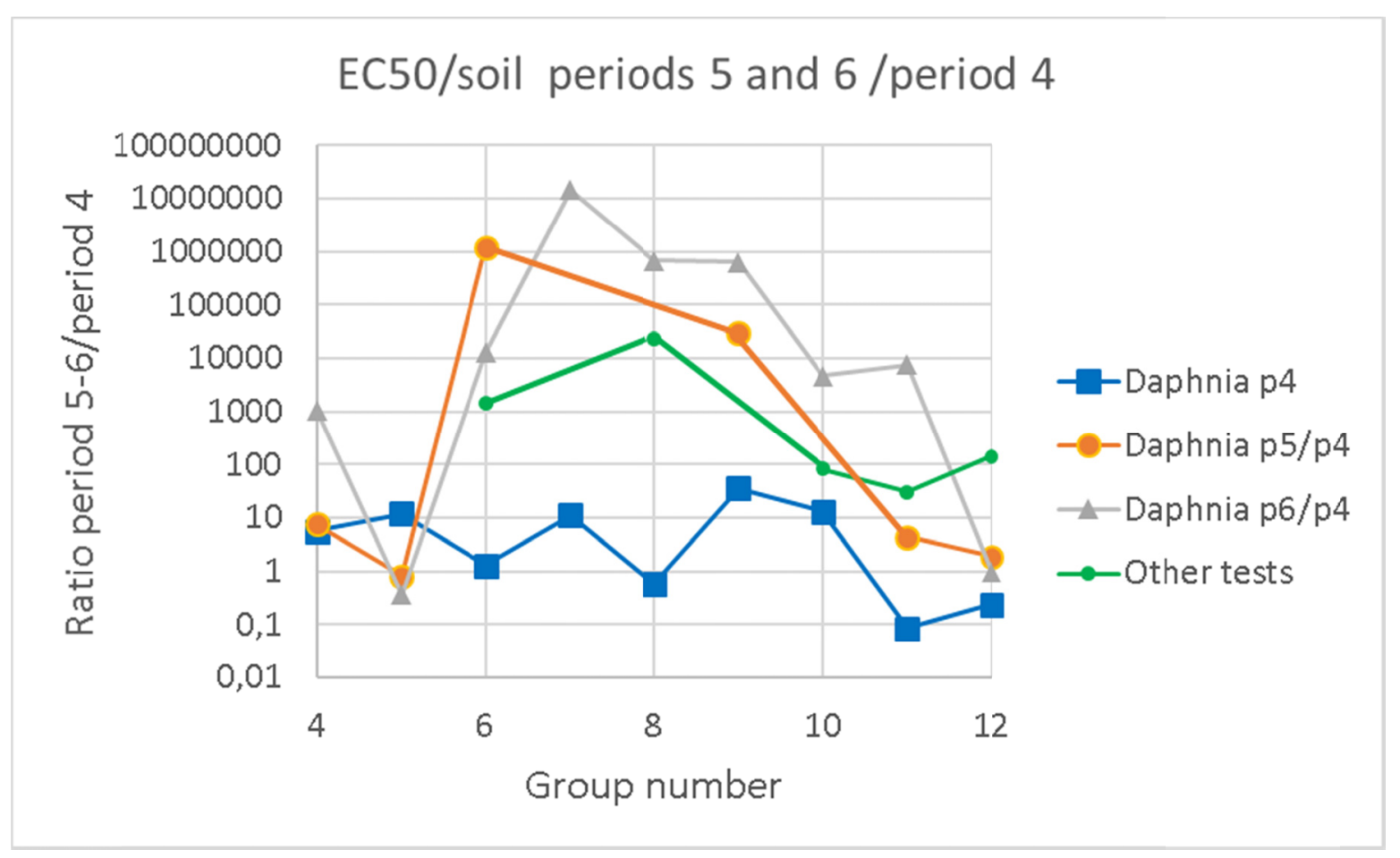

Figure 1. EC50 values for D. magna immobilization for elements in period system groups 4-12

Notes. Large circles and triangles give the ratios of EC50/(soil concentration) for elements in periods 5 and 6 , respectively, to that for the corresponding group element in period 4. For instance, for group 7, the ratio EC50/soil for Re in period 6 is near 1000000 times that for Mn in period 4. Squares represent the enhancement of the EC50 compared to the dissolved element concentration in natural water for elements in period 4 (see text). The small circles represent a combination of EC50/(soil concentration) for two other tests for periods 5 and 6 , given as a proportionality check for the main data.

The figure is based on the EC50 for D. magna (Okamoto et. al., 2014) divided by soil concentration for elements with group numbers 4-12. This quantity for elements with the given group number in periods 5 and 6 , respectively, has been divided by the corresponding measurement-based quantity for period 4 and that ratio is entered in the diagram. The underlying numbers are given in table 1.

The squares represent the dimensionless ratio EC $50 * 0,01 /$ (dissolved element concentration) for $D$. magna for elements of period 4. This quantity for elements in groups 4-10 has a geometrical mean of 3.6 and a range 0.6-36. The points demonstrate that a threshold concentration related to the dissolved element concentration may vary by less than a factor of 10 across elements in period 4. For elements in groups $11(\mathrm{Cu})$ and $12(\mathrm{Zn})$ that quantity is lower by about a factor of 10 .

The figure also shows the proportionality check for two other less data rich test conditions (geometrical average of two species and periods 5 and 6 , see section 2.3.1). The resulting pattern of that assessment is largely consistent with that of the data by Okamoto et. al., 2014.

The overall picture that emerges is that the tested species are 30-10000 000 times less sensitive to the highly siderophile elements (groups 8-10 in period 5 and 7-11 in period 6) than to the corresponding elements in period 4. The effect concentration for elements in these groups decreases approximately exponentially with the element's group number. D. magna is also generally considerably less sensitive to the highly siderophile elements in period 6 than to the corresponding elements in period 5. This is not an effect of the normalization to soil concentrations; these differ at most by a factor of 2.4 for the elements in corresponding groups (Ru-Os; $\mathrm{Rh}-\mathrm{Ir}$; Pd-Pt). For elements with group numbers below 7 the trend of the effect concentrations is less clear cut.

The results thus strengthen the contention that highly siderophile elements may be orders of magnitude less sensitive to biological effects than surrounding elements in the same period. 


\subsection{No-Effect for Soil Organisms}

The geometrical mean of thresholds from three sets of data (section 2.3.2) are given in figure 2. The thresholds are divided by the soil concentration of the element. As expected, thresholds for elements in period 4 are at a soil concentration of a few times the typical natural concentration (mean 2.2, range 0.6-5.8).

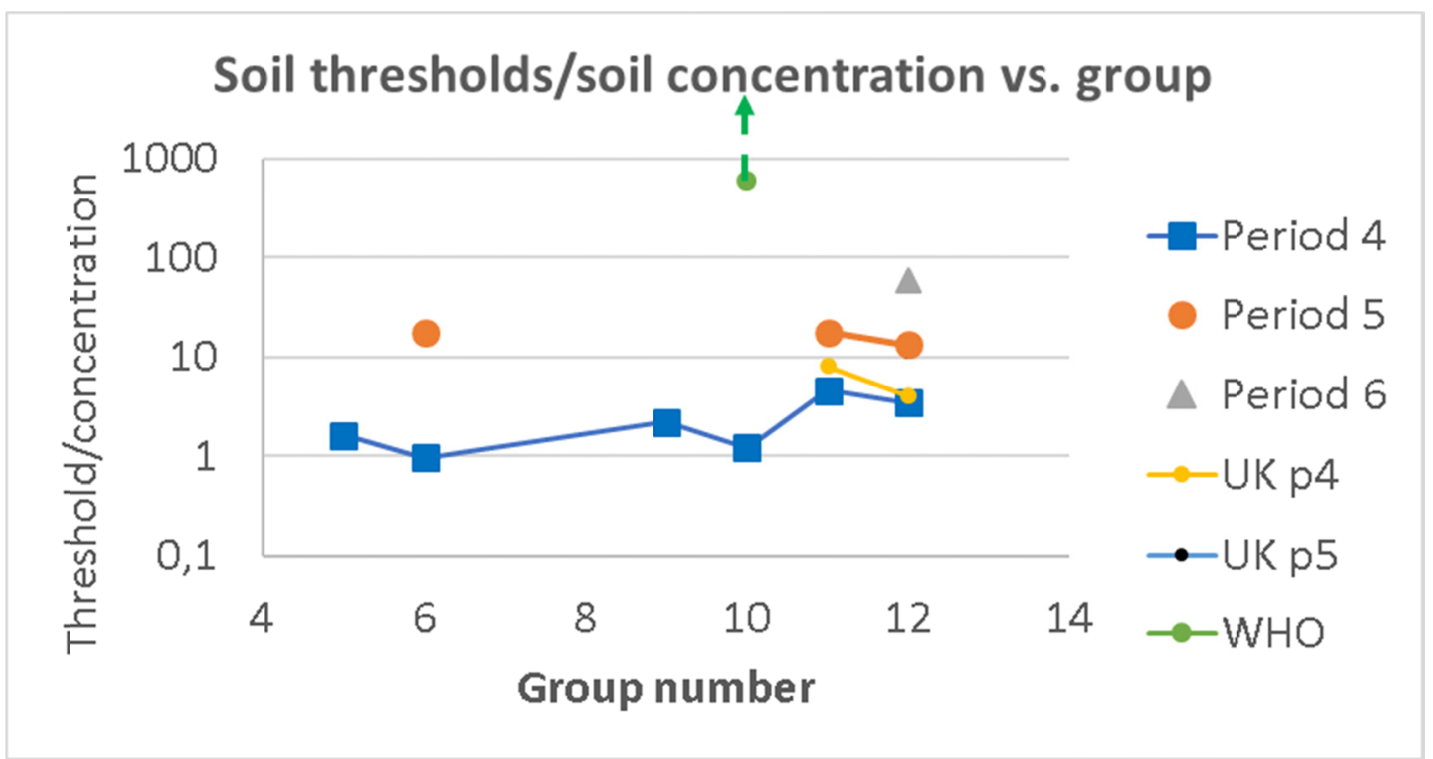

Figure 2. Thresholds for effects on soil organisms normalized to soil concentration for elements in groups 4-12

Notes. Large circles and the triangle give the ratios of threshold/soil concentration for elements in periods 5 and 6. Squares represent the enhancement of the threshold compared to the natural soil concentration for elements in period 4 (see text). The small circles represent the threshold/soil concentration for UK soils given as a proportionality check for the main data; the circle for $\mathrm{Cd}$ group 12 period 5 is hidden below that denoted period 5. The broken arrow denoted WHO represents Pt in period 6.

No information was found that would enable extrapolation to highly siderophile elements. However, the few points available for periods 5 and 6 are consistent with the findings for EC50 of D. magna that some organisms are much less sensitive to exposures to elements in periods 5 and 6 than to elements in period 4 . There is even an indication that the sensitivity to elements in period 5 is intermediate to that to elements in periods 4 and 6 . The thresholds derived for $\mathrm{Cu}, \mathrm{Zn}$, and $\mathrm{Cd}$ from the very extensive $\mathrm{UK}$ studies are very similar to those of the geometrical means for three countries (section 2.3.2). Note that the figure deals with thresholds for effects on soil organisms; default thresholds for soil remediation for some elements may be considerably lower and pertain to human health effects.

Regarding thresholds effects on soil organisms for siderophile elements, one can also find a parallel between the effects on a white soil worm species and those affecting the planktonic crustacean depicted in figure 1. The worm species is Enchytraeus crypticus, studied by Havelkova, Kovacova, Bednarova, Pikula, \& Beklova (2014). Enchytraeids are ecologically relevant soil organisms, due to their activity in decomposition and bioturbation in many soil types worldwide (Castro-Ferreira et. al., 2012). The ratio of EC50 for Enchytraeus crypticus over that of D. magna was similar (100-460) between Rh, Pd and Pt while the individual values of EC 50 ranged from 16 to 32000 . The worm response might possibly exhibit similar trends as those of the crustacean in figure 1 . The argument is however weak since single species data carry little weight as discussed in section 2.3.1.

Another vague indication derives from the statement "Aquatic and terrestrial plants are affected by platinum compounds at concentrations in the $\mathrm{mg} / \mathrm{litre}$ or $\mathrm{mg} / \mathrm{kg}$ range" (WHO, 1991). A Pt soil concentration of $1 \mathrm{mg} / \mathrm{kg}$ would be about 600 times higher than the mean natural soil concentration as given by the dot and broken arrow in figure 2.

The broken arrow in figure 2 represents $1 \mathrm{mg} / \mathrm{kg}$ and upwards. The $\mathrm{Hg}$ point at group number 12 in period 6 represents a decrease by about a factor of 3 per increment in group number compared with the $1 \mathrm{mg} / \mathrm{kg}$ point. This is similar to the corresponding decrease for Occupational period 6 in figure 3 . 


\subsection{Human Toxicity}

Figure 3 gives estimated tolerable intakes (permitted intake, upper limits of intake) divided by mean dietary intakes for all selected elements, derived according to section 2.3.3. The selected baseline estimate for period 4 for elements in groups 7-12 is 3.81 times the mean daily intake.

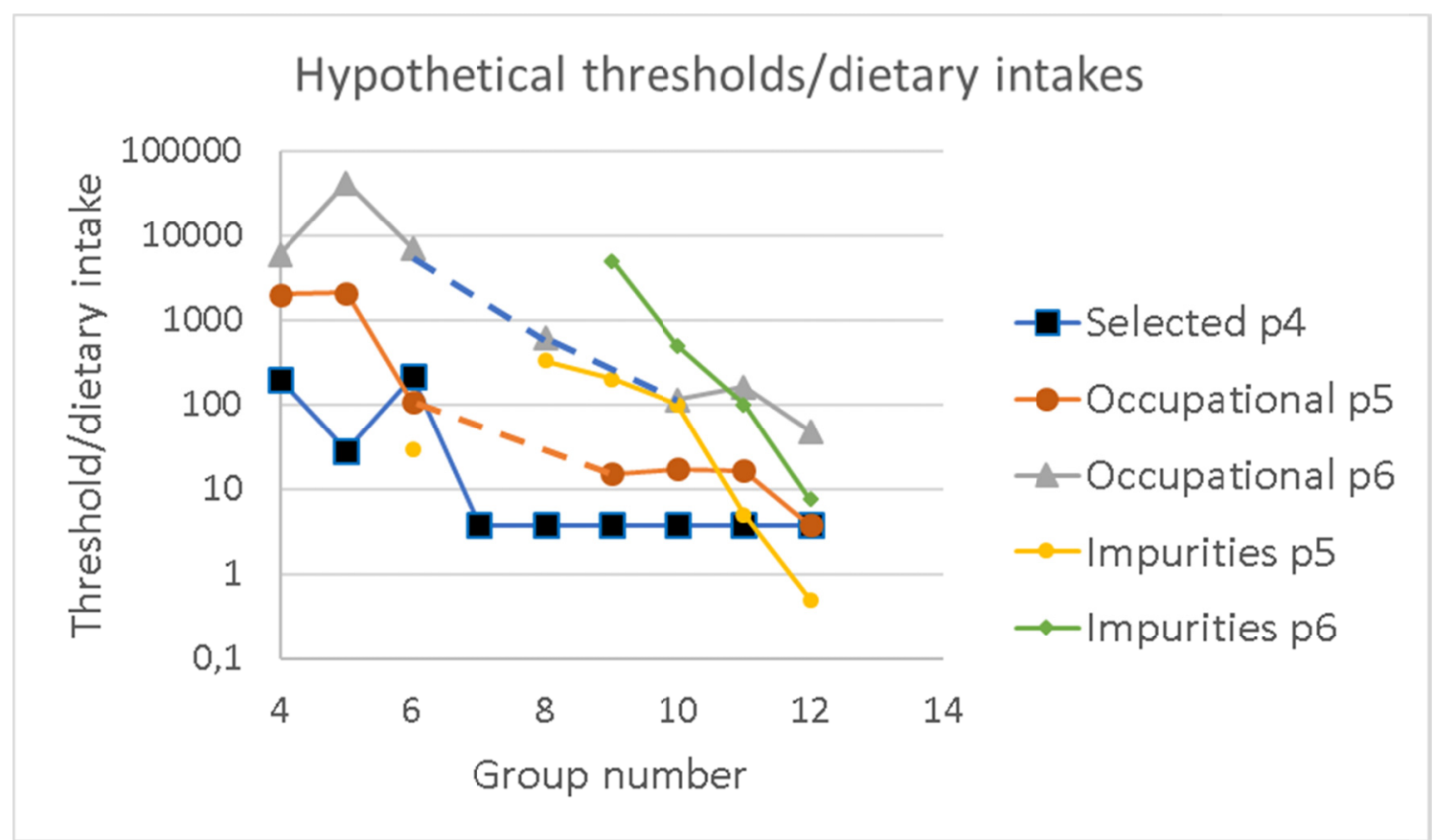

Figure 3. Derivation of hypothetical thresholds for human intake of highly siderophile elements

Notes. The main data are derived from occupational intake limits as described in section 2.3.4. Occupational inhalation limits have been converted to daily oral intakes. Large circles and triangles give the ratios of threshold/natural intake for elements in periods 5 and 6 . Squares represent the enhancement of upper limits of intake compared to the natural intake for elements in period 4 (see text). The small circles were derived from the thresholds for impurities in medical drugs divided by the daily intakes, given as a proportionality check for the main data.

\subsubsection{Upper Limits of Intake}

The squares in figure 3 represent upper limits of intake of elements for elements in period 4 . The limit is closely proportional to the mean daily intake for elements in groups 7-12, with a very small interelement standard deviation of $22 \%$. For elements in groups 4-6 (Ti, V, Cr), humans are quite tolerant. Sometimes reviewing bodies cannot find data to represent the hazards of these elements, so the thresholds of 30-200 times the daily intake are quite uncertain. For chromium, the data represent CrIII which dominates in food, but for intake of CrVI which is sometimes found in industrial settings, the threshold is only one-hundredth of that for CrIII.

\subsubsection{Hypothetial Thresholds Derived from Occupational Inhalation Thresholds}

The curves for periods 5 and 6 have large gaps, but the trends seem clear. The ratios of threshold intakes to mean dietary intakes for period 4 (Selected p4) are generally lower than those for period 5 (Occupational p5) which are generally lower than those for period 6 (Occupational p6). The distance between the curves is about a factor of 10 with large variations.

Using the data of figure 3, the hypothetical thresholds in table 2 below were derived. For Ru, Re, and Ir, where no occupational thresholds were available, the number is interpolated using neighboring elements. Differences to tolerable upper levels of intake for the general populations should be expected. The occupational thresholds namely apply to healthy workers and are derived for inhalation exposures. In contrast, tolerable upper levels of intake pertain to the general adult population including for instance vulnerable groups and should represent all pathways of exposure. 
Table 2. Hypothetical upper limits of intake for highly siderophilic elements

\begin{tabular}{lllllllll}
\hline Element & $\mathbf{R u}$ & $\mathbf{R h}$ & $\mathbf{P d}$ & $\mathbf{R e}$ & $\mathbf{O s}$ & $\mathbf{I r}$ & $\mathbf{P t}$ & $\mathbf{A u}$ \\
\hline Upper limit of intake divided by mean daily intake & $40^{*}$ & 15 & 17 & $2000^{*}$ & 600 & $250^{*}$ & 110 & 160 \\
Upper limit of intake $\mu$ g/day & $18^{*}$ & 8 & 17 & $60^{*}$ & 15 & $4^{*}$ & 20 & 160 \\
\hline
\end{tabular}

*Interpolated based on occupational exposures for neighboring elements

Figure 3 also contains data for periods 5 and 6 that were derived on the basis of impurities limitations. They should be much less certain than the data derived using occupational exposures, considering the extensive use of safety margins that would lead to erring on the side of safety. However, in many cases the thresholds are higher rather than lower than those from occupational exposures which is puzzling. But in common with the occupational ones, the thresholds from the impurity assessment decrease exponentially with group number and are consistently higher for period 6 as compared with period 5, in this case by a factor of about 10-30. The impurities data can serve to give some added confidence to the occupational data but may also raise a warning flag that uncertainties in the occupational data may be higher than expected.

\section{Discussion}

Section 3 (Results) shows that it has been possible to find parameters that describe credible trends of thresholds for health and environmental effects of transition metals across the periodic system of elements. The chosen representation has been that of thresholds as a function of groups and periods, divided by a measure of normal exposure. Such trends could only be found for the transition metals and uncertainties were large for groups number 4, 5 and 6 . The trends have enabled a preliminary assessment of the consequences of high environmental levels of the siderophile elements. The trends and the assessment are discussed in the following. Very scanty similar information has been found in other scientific publications. Therefore, it is essential that the tentative conclusions are scrutinized in further research.

\subsection{Thresholds across the Transition Metals}

Three sets of data have been derived pertaining to respectively D. magna EC50, thresholds for soil organisms, and upper limits of intake for human exposures. In all cases for elements in groups 7-11, relatively smooth curves were obtained of thresholds as a function of element group number and period, if the threshold were normalized to a measure of natural exposure. That measure was:

- element soil concentration for D. magna, as a proxy for natural water concentrations

- element soil concentration for soil living organisms

- mean daily element intake for human adult exposures.

In all cases, the variation is largest for groups 4-6 while the trends are more coherent for groups $7-11$. This is favorable for the extrapolation to the highly siderophile elements in groups 7-11.

There is also a tendency that for elements in the same periodic system group, the normalized thresholds are highest for period 6 , lower for period 5 and lowest for period 4 . This applies particularly to groups $7-11$. The difference between two adjacent periods is about

- for soil organisms, a factor of 4

- for limits of intake, a factor of 12 for period 6 relative to period 5

- for limits of intake, a factor of 6 for period 5 relative to period 4.

For D.magna the differences are larger but since only one species is involved, the difference varies and carries less weight. For the worm species discussed in section 3.2. there is also a weak indication that soil organisms might be less sensitive to $\mathrm{Rh}, \mathrm{Rd}$ and $\mathrm{Pt}$ than to period 4 elements.

The upper limits of intake ( $\mu \mathrm{g} / \mathrm{day}$, as opposed to the dimensionless normalized limits of intake) are nearly the same for elements in the same group in periods 5 and 6 . The ratio is 0.8 with a range from 0.3 to 1.3 . This is a quite narrow range considering that the differences between elements in the same period range up to a factor of 65 .

Judging by the rather smooth curves in figure 3, the uncertainties of the extrapolation resulting in table 2 should be relatively small. Bengtsson, 2018, estimated that mean dietary intakes should be accurate to within a factor of 3 in most cases, and such an uncertainty might not be inconsistent with the results in table 2 . A factor of 3 also 
envelopes well the variation in the threshold/soil concentration for period 4 elements in figure 2. It can also be noted that the geometrical mean of the ratio (occupational threshold)/ (limit of intake for adults in the general population) was 0.51 (section 2.3.4), suggesting that the thresholds discussed for human intakes may not be grossly wrong. However, the unexplained differences to the results from the assessment of impurities data may suggest that the uncertainties are larger.

4.2 Consequences for the Assessment of Large Exposures to Highly Siderophilic Elements

Bengtsson (2018), has pointed to the possibility that European soils may on average be enhanced by siderophile elements by a factor of up to 5 ( $\mathrm{Rh} 4.2$ times; Re 3; Pd, $\mathrm{Au}, \mathrm{Pt}, \mathrm{Ru}$ all more than 0.5 ). He also noted that large areas would then be exposed to 10 times the mean, thus 5 to 42 times for the mentioned elements. However, he made only very rudimentary assessments of the implications for soils and humans of such enhancements.

\subsubsection{Period 6 Elements Re, Os, Ir, Pt, Au}

The above analysis suggests that for period 6 elements (Re, Os, Ir, Pt, Au), upper limits of intake are more than 110 times higher than the normal dietary intakes. This seems to be an adequate margin to health effects of the current enhancements in European soils for these elements.

For soil organisms, little information has been found, but the WHO information of figure 2 suggest that the Pt threshold is at least 600 times higher than the natural concentration. This gap would seem to give an adequate safety margin for the mentioned mean European soil concentrations.

\subsubsection{Period 5 Elements $\mathrm{Ru}, \mathrm{Rh}, \mathrm{Pd}$}

In contrast, the normalized upper limits of intake are much lower for period 5 elements $(\mathrm{Ru}, \mathrm{Rh}, \mathrm{Pd})$. In the case of $\mathrm{Rh}$, large areas might entail intakes at 42 times the natural ones. This is almost 3 times higher than the upper limit of intake of 15 in table 2. Priority should thus be given to exploring further the consequences of enhanced exposures to Rh and possibly also to Pd. Such exploration should include assessment of the soil thresholds.

\section{Conclusions}

The current work suggests that highly siderophile elements entail much higher thresholds than other transition metals for effects on soil organisms and humans. The thresholds analyzed for period 4 elements are lower than those for elements in the corresponding group in period 5, which are in turn lower than those for period 6 elements. The analyzed thresholds in periods 5 and 6 decrease strongly and relatively monotonously with group number between groups 7 and 12, but still there may remain up to a factor of 10 difference for group 12 elements ( $\mathrm{Cd}$ and $\mathrm{Hg}$ in relation to $\mathrm{Zn}$ ).

The suggested decrease in sensitivity for siderophile elements may imply that for most elements, the present high enhancements of some highly siderophile elements in European soils are not of major concern. For rhodium and possibly palladium, however, the current levels of contamination might lead to effects on soil organisms and human health in limited areas with particularly high metal concentrations.

\section{References}

Aldenberg, T., \& Slob, W. (1993). Confidence limits for hazardous concentrations based on logistically distributed NOEC toxicity data. Ecotoxicology and Environmental Safety, 25, 48-63. https://doi.org/10.1006/eesa.1993.1006

ARCHE Consulting. (2019). Threshold calculator for metals in soil v2.0. Retrieved January 30, 2019, from https://www.arche-consulting.be/tools/threshold-calculator-for-metals-in-soil/

Avellan, A., Simonin, M., McGivney, E., Bossa, N., Spielman-Sun, E. ... Lowry, G. V. (2018). Gold nanoparticle biodissolution by a freshwater macrophyte and its associated microbiome. Nature Nanotechnology, 13, 1077. https://doi.org/10.1038/s41565-018-0231-y

Bengtsson, G. (2018). Past, present and future exposures from natural elements. In Proceedings of the global symposium on soil pollution 2-4 May 2018 FAO Headquarters Rome, Italy. Rome: Food and Agriculture Organization of the United Nations Full manuscript. Retrieved from http://www.fao.org/fileadmin/user_upload/GSP/GSOP18/Bengtsson_Environmental_full.pdf

Biesinger, K. E., \& Christensen, G. M. (1972). Effects of various metals on survival, growth, reproduction and metabolism of Daphnia magna. Journal of the Fisheries Research Board of Canada, 29(12), 1691-1700. https://doi.org/10.1139/f72-269

Botha, T. L., James, T. E., \& Wepener, V. (2015). Comparative aquatic toxicity of gold nanoparticles and ionic gold using a species sensitivity distribution approach. Journal of Nanomaterials. 
http://dx.doi.org/10.1155/2015/986902

Brooks, A. N., Turkarslan, S., Beer, K. D., Fang, Y. L., \& Baliga, N. S. (2011), Adaptation of cells to new environments. Wiley Interdiscip Rev Syst Biol Med., 3(5), 544-561. https://doi.org/10.1002/wsbm.136

California Department of Industrial Relations. (2019). Permissible exposure limits for chemical contaminants. Retrieved from https:/www.dir.ca.gov/title8/5155table_ac1.html

Canadian Centre for Occupational Health and Safety. (2019). Occupational Hygiene - Occupational Exposure Limits.

https:/www.ccohs.ca/oshanswers/hsprograms/occ_hygiene/occ_exposure_limits.html

Castro-Ferreira, M. P., Roelofs, D., van Gestel C. A., Verweij, R. A., Soares, A. M., \& Amorim, M. J. (2012). Enchytraeus crypticus as model species in soil ecotoxicology. Chemosphere, 87(11), 1222-1227. https://doi.org/10.1016/j.chemosphere.2012.01.021

CCME. (2019). Canadian Environmental Quality Guidelines. Retrieved from http://st-ts.ccme.ca/en/index.html

Cobelo-Garcia, A., Filella, M., Croot, P., Frzzoli, C., DuLaing, G., \& Zimmermann, S. (2015). COST action TD1407: network on technology-critical elements (NOTICE) - from environmental processes to human health threats. Environ Sci Pollut Res. https://doi.org/10.1007/s11356-015-5221-0

Day, J. M., Brandon, A. D., \& Walker, R. J. (2016). Highly siderophile elements in earth, Mars, the moon, and asteroids. Reviews in Mineralogy \& Geochemistry, 4(81), 161-238. http://dx..org/10.2138/rmg.2016.81.04

EFSA ANS Panel. (2016). EFSA Panel on food additives and nutrient sources added to food, Scientific opinion on the re-evaluation of gold $(\mathrm{E}$ 175) as a food additive. EFSA Journal, 14(1). https://doi.org/10.2903/j.efsa.2016.4362

EFSA. (2006). Tolerable upper intake levels for vitamins and minerals. Parma, Italy: European Food Safety Authority.

Retrieved

from http://www.efsa.europa.eu/sites/default/files/efsa_rep/blobserver_assets/ndatolerableuil.pdf

Fairbrother, A., \& McLaughlin, M. J. (2002). Metalloregions. Fact sheet on environmental risk assessment No 12. Published by the International Council on Mining and Metals (ICMM). Retrieved from http://www.icmm.com/document/46

FOREGS. (2005). Geochemical Atlas of Europe. Part 1 - Background information, methodology and maps. In R. Salminen (Ed.), Statistics. Espoo, Finland: Geological Survey of Finland. Retrieved from http://weppi.gtk.fi/publ/foregsatlas/article.php?id=15

Fratoddi, I., Venditti, I., Carnetti, C., \&Russo, M. V. (2014). How toxic are gold nanoparticles? The state-of-the-art. Nano Research, 8(8), 1771-1799.

Gaze, W. H., Krone, S. M., Larsson, D. G. J., Li, X. Z., Robinson, J. A., Simonet, P. ... Zhu, Y-G. (2013). Influence of humans on evolution and mobilization of environmental antibiotic resistome. Emerging Infectious Diseases, 19, 7. Retrieved from https://wwwnc.cdc.gov/eid/article/19/7/12-0871_article

Goldschmidt, V. (1937). The principles of distribution of chemical elements in minerals and rocks. The seventh Hugo Müller Lecture, delivered before the Chemical Society. Journal of the Chemical Society, 655-673. https://doi.org/:10.1039/JR9370000655

Havelkova, B., Kovacova, V., Bednarova, I., Pikula, J., \& Beklova, M. (2014). Impact of platinum group elements on the soil invertebrate Enchytraeus crypticus. Neuro Endocrinology Letters, 35(Suppl 2), 43-50. https://europepmc.org/abstract/med/25638365

ICH. (2014). ICH harmonised guideline. Guideline for elemental impurities. International Conference on Harmonisation of technical requirements for registration of pharmaceuticals for human use. Retrieved from https://www.ich.org/fileadmin/Public_Web_Site/ICH_Products/Guidelines/Quality/Q3D/Q3D_Step_4.pdf

IFA. (2019). Institut für Arbeitsschutz der Deutschen Gesetzlichen Unfallsversicherung. GESTIS International limit values. Retrieved from http://limitvalue.ifa.dguv.de/

Institute of Medicine, Food and Nutrition Board. (2001). Dietary reference intakes for vitamin A, vitamin K, arsenic, boron, chromium, copper, iodine, iron, manganese, molybdenum, nickel, silicon, vanadium, and zinc. Washington, DC: National Academy Press. Retrieved from https://ods.od.nih.gov/factsheets/Chromium-HealthProfessional/\#en10

IWRA. (2018). Developing a global compendium on water quality guidelines. Nanterre Cedex, France: 
$\begin{array}{lllll}\text { International } & \text { Water } & \text { Resources } & \text { Association. } & \text { Retrieved }\end{array}$ https://www.iwra.org/wp-content/uploads/2018/11/WQ-compendium-final-1.pdf

John, D. A., Seal, R. R. II, \& Polyak, D. E. (2017). Rhenium, Chapter P. In Schulz, K. J., DeYoung, J. H. Jr., Seal, R. R. II, \& Bradley, D. C. (Eds.), Critical mineral resources of the United States-Economic and environmental geology and prospects for future supply (pp. 1-49). U.S. Geological Survey Professional Paper 1802. https://doi.org/10.3133/pp1802P

Kim, S. W., Kwak, J. I., \& An, Y.-J. (2013). Multigenerational study of gold nanoparticles in Caenorhabditis elegans: Transgenerational Effect of Maternal Exposure. Environ. Sci. Technol., 47(10), 5393-5399.

Knapp, C. W., Callan, A. C., Aitken, B., Shearn, R., Koenders, A., \& Hinwood, A. (2017). Relationship between antibiotic resistance genes and metals in residential soil samples from Western Australia. Environ Sci Pollut Res, 24, 2484-2494.

Knapp, C. W., McCluskey, S. M., Singh, B. K., Campbell, C. D., Hudson, G., \& Graham, D. W. (2011). Antibiotic resistance gene abundances correlate with metal and geochemical conditions in archived Scottish soils. PLoS ONE 6,11, e27300. https://doi.org/10.1371/journal.pone.0027300

Martin, J.-M., \& Whitfield, M. (1983). The significance of the river input of chemical elements to the ocean. In Wong, C. S., Boyle, E., Bruland, K. W., Burton, J. D., \& Goldberg, E. D. (Eds.), Trace Metals in Sea Water (pp. 265-296). Plenum Press, New York. https://doi.org/10.1007/978-1-4757-6864-0_16

May, M., Drost, W., Germer, S., Juffernholz, T., \& Hahn, S. (2016). Evaluation of acute-to-chronic ratios of fish and Daphnia to predict acceptable no-effect levels. Environmental Sciences Europe, $28,16$. https://doi.org/10.1186/s12302-016-0084-7

MFE. (2019). Environmental guideline value database. Ministry for the Environment New Zealand. Retrieved from

http://www.mfe.govt.nz/land/risks-contaminated-land/managing-contaminated-land/contaminated-land-man agement-guidelines- 0

Ministry of the Environment, Finland. (2007). Government decree on the assessment of soil contamination and remediation needs. Retrieved March 1, from https://www.finlex.fi/en/laki/kaannokset/2007/en20070214.pdf

Moreno-Garridon, I., Pérez, S., \& Blasco, J. (2015). Toxicity of silver and gold nanoparticles on marine microalgae. Marine Environmental Research, 111, 60-73 https://doi.org/10.1016/j.marenvres.2015.05.008

Okamoto, A., Yamamuro, M., \& Tatarazako, N. (2014). Acute toxicity of 50 metals to Daphnia magna. Journal of applied toxicology, 35(7), 824-830. https://doi.org/10.1002/jat.3078

Ontario Ministry of Labour. (2019). Review of occupational exposure limits in Ontario: Current and proposed exposure limits. Retrieved from https:/www.labour.gov.on.ca/english/about/consultations/oels/table.php

Qie, Y., Chen, C., Guoa, F., Mo, Y., Sun, F., Wang, H. ... Giesy, J. P. (2017). Predicting criteria continuous concentrations of metals or metalloids for protecting marine life by use of quantitative ion characteristicactivity relationships-species sensitivity distributions (QICAR-SSD). Marine Pollution Bulletin, 124(2), 639-644 Retrieved from https://www.usask.ca/toxicology/jgiesy/pdf/publications/JA-981.pdf

Safe work Australia. (2018). Workplace exposure standards for airborne contaminants. Canberra, Australia: Safe Work Australia. Retrieved from https://www.safeworkaustralia.gov.au/system/files/documents/1804/workplace-exposure-standards-airborne -contaminants-2018_0.pdf

Smith, K. S., \& Huyck, H. L. O. (1999). An overview of the abundance, relative mobility, bioavailability, and human toxicity of metals. Reviews in Economic Geology, 6, 29-70. Retrieved from http:/citeseerx.ist.psu.edu/viewdoc/download?doi=10.1.1.437.5108\&rep=rep1\&type

Swedish environmental protection agency. (2016). Naturvårdsverkets generella riktvärden för förorenad mark. (In Swedish). Stockholm, Sweden: Naturvårdsverket. Retrieved from http:/www.naturvardsverket.se/upload/stod-i-miljoarbetet/vagledning/fororenade-omraden/berakning-riktv arden/generella-riktvarden-20160707.pdf

UK Water Industry Research Limited. (2007). Effects of sewage sludge applications to agricultural soils on soil microbial activity and the implications for agricultural productivity and long-term soil fertility: phase III. London, United Kingdom: UK Water Industry Research Limited. Retrieved from 
http://randd.defra.gov.uk/Document.aspx?Document=SP0130_6505_FRP.pdf

UNEP. (2013). Environmental risks and challenges of anthropogenic metals flows and cycles. Nairobi, Kenya: United Nations Environment Programme. Retrieved from http://www.unep.org/resourcepanel-old/Portals/24102/PDFs/Environmental_Challenges_Metals-Full\%20Re port_150dpi_13092

USGS. (2018). Commodity Statistics and Information. Gold. Retrieved from https://minerals.usgs.gov/minerals/pubs/commodity/gold/mcs-2018-gold.pdf

Walker, J. D., Enache, M., \& Dearden, J. C. (2003). Quantitative cationic - activity relationships for predicting toxicity of metals. Environmental Toxicology and Chemistry, 22, 1916-1935. Retrieved from https://setac.onlinelibrary.wiley.com/doi/epdf/10.1897/02-568

Wang, W.-X. (2013). Dietary toxicity of metals in aquatic animals: Recent studies and perspectives. Chinese Science Bulletin, 58(2), 203-213. $\quad$ Retrieved from https://link.springer.com/article/10.1007/s11434-012-5413-7

Wang, Y., Wu, F., Liu, Y., Mu, Y., Giesy, J. P., Meng, W., ... Dand, Z. (2018). Effect doses for protection of human health predicted from physicochemical properties of metals/metalloids. Environmental Pollution, 232, 458-466. https://doi.org/10.1016/j.envpol.2017.09.065

Weaver, J. L., Tobin, G. A., Ingle, T., Bancos, S., Stevens, D., Rouse, R., ... Tyner, K. M. (2017). Evaluating the potential of gold, silver, and silica nanoparticles to saturate mononuclear phagocytic system tissues under repeat dosing conditions. Particle and Fibre Toxicology, 14(25). https://doi.org/10.1186/s12989-017-0206-4

WHO. (1991). IPCS Environmental Health Criteria. Platinum. Geneva, Switzerland: World Health Organisation. Retrieved from http://www.inchem.org/documents/ehc/ehc/ehc125.htm\#SectionNumber:10.2

Winkler, H. C., Notter, T., Meyer, U., \& Naegeli, H. (2018). Critical review of the safety assessment of titanium dioxide additives in food. Nanobiotechnology, 16, 51. https://doi.org/10.1186/s12951-018-0376-8

Yah, C. S. (2013). The toxicity of gold nanoparticles in relation to their physiochemical properties. Biomedical Research, 24(3), 400-413. https://www.alliedacademies.org/articles/the-toxicity-of-gold-nanoparticles-in-relation-to-their-physiochemi calproperties.pdf

Zientek, M. L., Loferski, P. J., Parks, H. L., Schulte, R. F., \& Seal, R. R., II. (2017). Platinum-group elements, chap. N. In Schulz, K. J., DeYoung, J. H., Jr., Seal, R. R., II, \& Bradley, D. C. (Eds.), Critical mineral resources of the United States-Economic and environmental geology and prospects for future supply (pp. N1-N91). U.S. Geological Survey Professional Paper 1802. https://doi.org/10.3133/pp1802N

\section{Copyrights}

Copyright for this article is retained by the author(s), with first publication rights granted to the journal.

This is an open-access article distributed under the terms and conditions of the Creative Commons Attribution license (http://creativecommons.org/licenses/by/4.0/). 